Turning points in a qualitatively different social space: young adults' reflections of alternative provision

Andrew Malcolm

Applied Social Studies, University of Bedfordshire, Luton, UK

andrew.malcolm@,beds.ac.uk

ORCID ID: orcid.org/0000-0002-8137-8122 


\section{Turning points in a qualitatively different social space: Young adults' reflections of}

\section{Alternative Provision}

There is a wealth of evidence suggesting that after being marginalised and excluded from school young people who attend Alternative Provision settings report positive relationships and experiences of learning. There is however very little research which explores the longer term outcomes of attending this sort of provision. Retrospective life history interviews were undertaken with 18 young adults in their early to mid-20s who had attended Alternative Provision in England. Interviews focused on schooling, exclusion, attending Alternative Provision and the impact of this on what they had done since leaving school up to their present situation. Analysis showed that the experience of attending Alternative Provision frequently constituted a turning point in a young person's life story. This was due to the qualitatively different kind of social space experienced there.

Keywords: alternative provision, careership, exclusion, pupil referral unit

\section{Introduction}

Alternative provision (AP) is attended by young people who are marginalised (O Gorman, Salmon, and Murphy 2015) and excluded from mainstream schooling. The findings reported here are drawn from a doctoral research project (Malcolm, 2015) which took place across an English county and involved the various types of AP setting found in the English context. These include Pupil Referral Units (PRUs), AP free schools, AP academies and other AP settings which may or may not be registered as independent schools (DfE, 2018).

Pupils who pose a risk to schools' outcomes experience "powerful sorting in the English secondary education system" (Feltcher, Strand, and Thomas 2015, 19). These pupils are the result, the wasted lives, of the neo-liberal, marketised English schooling system (Mills, Renshaw 
and Zipin 2013). However, those working in AP see hope in these young lives and work to support them through their education (Garner 1996; Grundy and Blandford 1999; Farouk 2014; Malcolm 2018a). The research reported below sought to explore the experiences of those who had attended AP and the impact they perceive it to have had on their opportunities and experiences in life since then. Analysis showed that the experience of attending AP frequently constituted a turning point in a young person's life story. This was due to the qualitatively different kind of social space experienced there (Pomeroy 1999). The discussion will explore how far and in what ways the positive regard of staff in AP settings can make up for the structural exclusion these young adults faced in their experiences of schooling.

\section{Literature review}

There is a great deal of research which explores the experiences of young people attending AP and indeed significant consensus across this body of research. There is however very little research which explores the longer term impact of attending AP (Thomson 2014). There are a few exceptions which will be considered below. This section will begin by reviewing the reported experiences of those who attend AP settings. Twenty one studies are referenced in this review of the literature, this includes two lit reviews, fourteen (case) studies making use of various methods of data collection (interviews, the analysis of documents and records, and observation) on singles sites $(\mathrm{N}=5)$ and multiple sites $(\mathrm{N}=9)$. Two studies with just staff or professionals participating, one write up of a study across the whole of Wales, one study which made use of secondary data and a cohort analysis of young people permanently excluded from PRUs and Special Schools. Discounting the literature reviews, of the nineteen other studies only one was quantitative (Lumby 2012). The other eighteen studies were qualitative in orientation although half of there made use of documents or school records. This prominence of qualitative 
studies has also been noted by Thomson (2014) and suggests there is a need for large scale quantitative study of these issues.

\section{Young peoples' experiences of attending alternative provision}

Research suggests that the relationships that young people experience in AP are the fundamental base from which all else is built (Pomeroy 1999; McCluskey, Riddell, and Weedon 2015; Pirrie et al. 2011; O Gorman, Salmon, and Murphy 2015). Indeed, Attwood, Croll, and Hamilton (2004) noted that relationships tend to be involved in both estrangement and re-engagement in education (also Pillay, Dunbar-Krige, and Mostert 2013). Poor, or a lack of, relationships in mainstream settings are frequently reported as important in placement breakdown (Attwood, Croll, and Hamilton 2004; Trotman, Tucker, and Martyn 2015; Lumby 2012). Whereas positive, respectful relationships are reported by young people attending AP settings (Cajic-Seigneur and Hodgson 2016; Trotman, Tucker, and Martyn 2015; McCluskey, Riddell, and Weedon 2015, Morgan et al. 2015; Pomeroy 1999) and are foundational to reconnecting with young people and engaging them in learning (Morgan et al. 2015; McGregor et al. 2014; McGregor and Mills 2012; Lumby 2012; Cullen and Monroe 2010; Attwood, Croll, and Hamilton 2004).

Built upon this foundation of relationships, young people who attend AP settings refer positively to characteristics of both staff and the environment itself. Schooling in AP settings is undertaken on a far smaller scale than mainstream (Thomson 2014; O Gorman, Salmon, and Murphy 2015) which leads to a calmer atmosphere and approach (Trotman, Tucker, and Martyn 2015; Nicholson and Putwain 2015). There is time to listen to, explore and work through any challenging dynamics which emerge within the school population (O Gorman, Salmon, and Murphy 2015; Cajic-Seigneur and Hodgson 2016; Solomon and Thomas 2013; Nicholson and Putwain 2015; McGregor et al. 2014). There is flexibility within the curriculum such that it can 
be personalised, through the young person's choice, to ensure its relevance to their experiences and aspirations (Thomson 2014; Trotman, Tucker, and Martyn 2015; Nicholson and Putwain 2015; McCluskey, Riddell, and Weedon 2015; McGregor et al. 2014; McGregor and Mills 2012). Young people repeatedly report being treated like adults in AP settings; there is freedom but also responsibility (Cajic-Seigneur and Hodgson 2016; McCluskey, Riddell, and Weedon 2015). Alongside this, familial descriptors are frequently used by young people in their descriptions of staff (O Gorman, Salmon, and Murphy 2015; Nicholson and Putwain 2015) and a family atmosphere has been recognised as characteristic of AP (Thomson 2014).

The respect that comes along with the more grown up relationships with staff is highly valued by young people who attend AP (Pomeroy 1999; Nicholson and Putwain 2015; McCluskey, Riddell, and Weedon 2015; Morgan et al. 2015). Alongside respect there is a willingness to engage in humour and banter providing a safe space for young people to explore the dynamics of grown up relationships and to learn how and when to engage in these practices (Trotman, Tucker, and Martyn 2015; Attwood, Croll, and Hamilton 2004; Thomson and Pennacchia 2014). The characteristics of staff that are reported as important in the research are that they are committed and highly skilled (Thomson 2014). The young people in their care describe them as supportive and encouraging and perceive that they value them (Cajic-Seigneur and Hodgson 2016; Trotman, Tucker, and Martyn 2015; Nicholson and Putwain 2015; O Gorman, Salmon, and Murphy 2015). This care that young people perceive in AP settings is often constructed by making comparison to mainstream where this was something that was lacking in their experience (Pomeroy 1999).

\section{The impact of attending alternative provision}


Not all AP provides a positive experience for those young people who attend, yet the balance of reported opinion from research undertaken with young people in these settings is generally weighed far further toward positive experiences than negative. Indeed, despite going on to raise concerns about the intersection of children's rights with school exclusion and AP, McCluskey, Riddell, and Weedon $(2015,6)$ recognise that many young people they interviewed were 'fulsome in their praise of the academic experience and pastoral care' found in AP settings. Thomson (2014) has undertaken a thorough review of the research on AP which includes a section on what is known about outcomes and their relationship to this educational experience. In essence the answer is not enough. Whilst there are reviews of individual programmes very few of these are longitudinal. The lack of large-scale study of these issues is in part down to the difficulty of tracking young people who have attended AP. In relation to practice Thomson's review suggests that programmes focussed on reintegration and post school planning are more effective than those prioritising literacy and numeracy skills. In terms of impact, studies of AP have shown improvements in attendance, engagement and behaviour (Thomson 2014). Longer and more frequent participation in AP may have longer lasting effects and short term improvements are reportedly hard to maintain when returning to the context of previous conflict (Thomson 2014). Young peoples' longer-term success would seem to be mediated by their selfbelief, the support which is available to them and which they are willing to take up from friends, family and or external sources (for example a key worker) (Thomson 2014).

These findings would seem to suggest that for future steps to be successful those involved need to be planning for the young person's next step. There needs to be time for the culture found within AP settings to have an impact and for improved attendance and behaviour to influence future engagement. There also needs to be space for young people to tell and believe in 
their own story and, some level of on-going support as and where needed, although this may not be necessary if friends and family are in a position to provide this.

Since Thomson's review in 2014 a number of other studies have been published. Although none of the papers address the longitudinal issue there are elements in the findings of these papers which confirm the themes of improved behaviour and development of selfconfidence. A review undertaken by O Gorman, Salmon, and Murphy (2015) suggests that staff taking the time to listen leads to young people conforming to behavioural expectations. Indeed, Morgan et al. (2015) suggest the social, emotional and academic learning are intertwined, and that the mutual respect and care which can be experienced in AP settings leads to reengagement. The potential for the development of self-confidence in AP settings is confirmed by Nicholson and Putwain (2015) who also suggest maturity, becoming calmer and developing an appreciation of the value of education as outcomes of AP.

There is emerging tension in the literature between authors who conceptualise AP as a positive educational setting and those who express concerns about ineffectiveness and inequality. Internationally a number of authors are beginning to conceptualise AP as a site where young people have a chance to become someone different (Thomson and Pennacchia 2015) and to come to see greater possibilities for their future (McGregor et al. 2014). This is in line with previous research which considered AP sites as having the potential to provide 'a schooling experience that was positive enough to make these young people want to reconnect to learning and allow them to dream different futures for themselves' (McGregor and Mills 2012, 854). Indeed, Morgan et al. (2015) have gone as far as to suggest that 'relational ways of being an educator are vital to support the creation of lifelong learners' $(2015,1)$, theorising that attending AP can have long-term impact. 
This positive view of the potential of AP sits in contrast to the work of Jalali and Morgan who whilst agreeing about pupils' perceptions of behavioural improvements in AP suggested that 'for the majority of students, the thought processes guiding their behaviour remain unchanged ... Such thinking indicates the ineffectiveness of PRU remits in supporting long term behaviour change' (Jalali and Morgan 2017, 9). These concerns sit alongside those of other researchers who have written about AP as working to the lowest common denominator leading to low expectations and limited possibilities (McCluskey, Riddell, and Weedon 2015). Concerns have also been raised about gendered practice found in AP settings (Russell and Thomson 2011) and articulations of AP as reproducing disadvantage (Gazeley 2010).

\section{Theory}

The discussion of the young adults' experiences of AP is underpinned by the work of Phil Hodkinson on 'Careership' which utilises Bourdieu's field theory. For a somewhat similar connection between 'Careership' and the educational experiences of young people in the youth justice system see Lanskey (2014). There are three dimensions to 'Careership', outlined below, which provide a helpful framework for conceptualising AP as an important phase in the lives and career journeys of the young adults interviewed for this research.

The first dimension of 'Careership', 'horizons for action', locates the individual in their social context and considers their relationship to the position they inhabit. An individual not only makes decisions in a particular context but also comes to embody certain dispositions which are the product of their decisions and experiences. These dispositions shape future decisions and are in part the embodiment of the social structures in which the individual exists. The notion of a 'horizon for action' is helpful in that many things will be visible, but some will be more 
discernible than others. There will also be a wider world that is not visible to the individual from their current position. Hodkinson recognises individuals':

positions within and in relation to the field and their actions and dispositions contribute to the on-going formation and reformation of the field (Hodkinson 2008, 5).

This recognises that whilst an individual's context limits their opportunities to those within their 'horizons for action', any individual also plays an active part in the perpetuation, and sometimes the disruption, of the current order. Hodkinson notes that a person's 'horizons for action' are not set in stone; change can be precipitated by a change of disposition, position or field (Hodkinson 2008). Whether the move from mainstream to AP is conceptualised as a change of position (within the broader education system) or a change of field (from one educational establishment to another) there are important implications here for conceptualising the effect of attending AP.

The 'decision making process', the second dimension, explicates the relationship between the dynamics in the field and the decisions which individuals make. It is shaped by what is termed 'pragmatic rationality'. This understands that decisions made are not simply rationally discussed and thought through. Decisions are embodied and as such will be shaped by 'practical, physical, emotional and affective aspects' (Hodkinson 2008, 9) which can be hard to separate out. Decisions are understood to often be based on partial information, usually from trusted individuals rather than official sources. Indeed, it is not infrequent for good fortune to play a part in which decisions are made and career options are significantly shaped by the resources available to any individual - not only economic capital but also social connections and cultural understanding.

The final dimension, 'routines and turning points', views careers as something to be understood over the long-term where periods of stability (routines) will be broken up with 
occasional moments of significant career change (turning points). In later reflection on his early work Hodkinson suggests that routines and turning points would likely only be discernible in retrospect. Turning points, rather than being a moment in time or an event, involve the build-up to a decision and working through of the outcomes. Indeed, Hodkinson notes that a turning point can often be longer than 18 months (Hodkinson 2008). That turning points will only be fully recognisable in retrospect sits well with this study's use of retrospective interviews with young adults who attended AP.

\section{Method}

The main research question guiding the doctoral research from which this paper is drawn (Malcolm, 2015) was twofold exploring the nature of AP schooling across an English county and the effect of this kind of educational experience on the pupils who attend AP. Life history interviews were conducted with young adults who had previously attended AP to explore their time at school and AP and their subsequent life experiences. Transcribed interviews were analysed by developing a case study for each young adult as well as undertaking a thematic analysis.

\section{Context and participants}

The research first involved gaining access to contact details for young adults before contacting, arranging and undertaking interviews. Access to contact details was negotiated with alternative providers who had taken part in the larger doctoral research project from which these interviews are drawn (Malcolm 2015). In total, names and at least partial contact details for 67 young adults were explored. Of these 67 some form of initial contact, often indirect, was established with 40. Indeed, of these 40 it was not possible to establish contact with the young adult in twelve cases. Of the remaining 28 , four were busy or not interested in taking part, and seven interviews were 
arranged but not attended. A total of 18 (17 plus a trial) interviews were successfully undertaken. This represents a success rate of just over a quarter from initial contact details and where initial contact was made just over four in ten young adults took part. Although on a smaller scale this is comparable if not slightly better than the work of Kilpatrick, McCartan, and McKeown (2007) who undertook a longitudinal study with young people who had attended AP settings. After young people initially agreed to take part, their contact rate dropped to just below a third over one and a half years. That the contact rate in the present study is slightly higher than this speaks to the value of this research and more generally of undertaking retrospective interviewing with hard to reach population groups.

Of the 18 young adults who participated in this research 11 were male and 7 female and 15 of the 18 were from white backgrounds. None of the young adults had been referred to AP during primary school although two had been home tutored. Two young adults had only attended post-16 AP. Of the 16 young adults who were referred to AP during their time in secondary school two were referred in year 7, five in year 8 , four in year 9 and five in year 10 . Seven of the 16 young adults attended just one AP setting, four attended two settings, two attended three settings with the remaining three young adults attending four, five and six settings respectively. Upon completing schooling at the age of 16 ten young adults had been in AP settings, two had been dual registered at both an AP and a mainstream school, two had finished in mainstream, one in a special school and one had become self-taught at home but had taken exams in an AP. Six had experienced unsuccessful reintegration into MS and of the two who finished in MS one had attended just one AP setting, the other had attended two and both returned for year 11 .

The research process was agreed by a university ethics committee and informed consent was gained from each young adult who took part. Participants were made aware that they could 
withdraw from the research at any point and were asked whether they would be happy for the interview to be audio recorded. All data was stored securely and names of participants and schools have been anonymised using pseudonyms.

\section{Data collection and analysis}

The interviews were conducted between December 2013 and July 2014 with the vast majority undertaken on the university campus and a small number conducted in other appropriate public places. An informal interview structure was used in the life history interviews with the young adults. These pivoted around the young adult's exclusion from mainstream and time in alternative provision so as to gain an idea of how alternative provision had impacted their life since attending. The interviews were started with the following introduction:

I want to talk about going to alternative provision, what that was like, what you have done since leaving, further courses or education, jobs, hobbies, and experiences, where you are now and if you think your time at alternative provision has had anything to do with any of the above.

After briefly asking about their current situation participants were asked to tell the story of their schooling, starting wherever seemed most relevant through attending AP and then up to the present day.

Asking about the schooling of a group of participants who have had challenging educational experiences necessitated that the researcher build rapport with interviewees. This was facilitated by the researcher's experience of working in AP settings and by making use of a semi-structured interview process. This meant that the researcher could engage with and respond to whatever the participants raised in their interviews but also that characteristics discussed in this paper are things picked up or covered in the interview process rather than necessarily asked 
about directly. It is however thought that the experiences the young adults perceive as relevant will have been mentioned and that the records collected in the research process provide sufficient evidence for the analysis undertaken here. This is because the analysis of these accounts focused on the meaning young adults made of their time in alternative provision particularly in relation to subsequent life experiences.

The analysis of the interview transcripts involved drawing up a case study for each young adult as well as a thematic analysis. The case studies helped to foreground the narrated experiences of each young adult. Thematic analysis was undertaken using NVivo to aid the development of codes which were then rationalised into themes. This was an iterative process with codes and findings developed from the data collected with the generation of theoretical insight in mind (Hutchinson et al. 2010).

Given the research reported here was undertaken for the authors professional doctorate it is important to consider issues of reflexivity and positionality. Although this was not 'insider research' the author did have a level of existing and on-going relationship with actors in the local AP network. For a ful account of these issues see Malcolm (2015). Suffice to say here that the findings and theoretical insight generated by this project went far beyond any of the initial ideas and experience of practice which the author bought to the project.

\section{Findings}

The findings will be structured in three parts. The experiences that the young adults reported within and in relation to their schooling will be reviewed before moving on to consider the young adults' retrospective reflections on AP. Finally, elements in their experiences which have influenced their trajectories when moving on into adult life will be considered.

\section{Experiences in relation to schooling}


The experiences of those interviewed were many and varied. Of the eighteen young adults interviewed four had experienced being taken into care. Additionally, one mentioned that they were nearly taken into care, another had been assigned a social worker and lived at a friend's house for a time, one had attended a residential special school during the week, and another walked out of home at the age of seventeen and moved into a hostel. Two young adults had received support from Child and Adolescent Mental Health Services (CAMHS) and another two had undertaken caring responsibilities when growing up. This gives a good gauge of the level of instability which is often present in the lives of the young people who attend AP schools (McGregor and Mills 2012) .

Eight of the eighteen interviewees had been permanently excluded from mainstream school. Seven out of the eighteen young adults had been issued with statements of special educational needs and ten young adults had experienced bullying while in mainstream school. Significantly, eight of the ten young adults who were not permanently excluded had experienced bullying suggesting a need to focus on situations where head teachers' use their power to direct pupils off the school site into AP (see also Malcolm 2018b). Bullying is an issue that is broadly missing from discussions of exclusion and AP although McCluskey (2008) and Osler et al. (2002) mention this in relation to self-exclusion from school.

\section{Retrospective reflections on attending $A P$}

In line with research undertaken with young people attending AP the young adults who took part in this research reflected on AP as a qualitatively different social space (Pomeroy 1999). This was broadly conceived of in terms of the relationships in AP and the flexibility found there. These themes will be considered in turn before consideration of the negative experiences recalled by the young adults. 


\section{Relationships}

The young adults' retrospective accounts of attending AP were very much in line with findings in the existing research. Relationships were of fundamental importance and were intrinsically connected to many of the other characteristics of AP that were discussed in the interviews. In relation to the small scale of AP schooling, young adults focussed on being known by others: you get to know people a bit better (Jeremy)

Indeed, in line with existing research (Trotman, Tucker, and Martyn 2015; Nicholson and Putwain 2015) this small scale and relational knowledge meant difficulties were more easily addressed:

In a smaller school like Bowden it's a bit, it's a bit closer, you can work out the weak links quite easier ... work different ways out of how to change it (Sam)

The small scale also frequently meant that staff had more time to interact with students: they're not in a hurry to get away from you (Sam)

And

For the most part the teachers just made you feel like you weren't an inconvenience, um, like the mainstream school system can sometimes make you feel ... it does definitely make a big difference (Liz)

When describing relationships in AP many of the young adults articulated AP as a family or homely environment, this is common in the literature (O Gorman, Salmon, and Murphy 2015; Nicholson and Putwain 2015; Thomson 2014). One interviewee made connections between relationships, learning and the integration of new arrivals into the centre:

when you was new you wasn't really disrespectful to them [staff] because everybody has a really good relationship with them (Nadia) 
Young adults also described encouraging relationships where staff had the time to care. This could be in educational situations where they had struggled to understand something or where a teacher took a real interest in their work. These relationships and their impact could be almost imperceptible, one young adult, primarily referring to relationships with staff, recalled that: talking to people and just being with people helped quite a lot ... even if you couldn't get your words out, people still listened to you (Josh)

Indeed, there were a number of young adults who had experienced bullying in school who mentioned that in AP they learnt to interact with and talk to people again, this will be developed below in the section on the impact of AP. A number of young adults experienced care and encouragement as almost overlapping experiences in AP:

a lot of people that were there cared, they just really wanted you to get, you know to go somewhere and to do something. So it was nice to have that feeling that, you know, that other people did believe in you (Emily)

When asked how he knew staff cared one young adult framed this as an almost embodied experience:

you just know they care, you can tell when people don't care, it's the negligence you can feel it, but they cared, more than anyone in my life ever has. And they still do now (Carl) Carl's last few words reflect a level of on-going relationship with the staff at his AP. Indeed, a number of the young adults who were involved in this research were put in contact with the researcher after visiting their old provision. On-going support is something that was discernible for a number of other young adults who had returned to post-16 courses at their AP. One interviewee who had a history of bullying and school refusal had disengaged from their AP in Year 11 after initial attendance. After getting back in touch with his old AP and disengaging 
again they agreed to give him a final opportunity to attend but only if he also enrolled in college - a process which they supported him through. Reflecting on this he said:

Great guys, really, they changed my life really. They're the ones that said you need to do it, I did it, did my first year of electrical, and I passed, distinctions throughout the whole course and I was like well happy, you know, going through nothing to distinction, Maths, English, ICT (Josh)

He went onto a level two course but then dropped out due to mental health difficulties. A short while later he reengaged in evening classes at a college to complete his level two qualification and at his interview was well on his way towards gaining a diploma:

I'd never ever dream of having a diploma in my life and now I'm going to do it (Josh) Interestingly, at least one other young adult used evening classes to progress their career. It would seem that the caring relationships in AP have the potential to both engage students in their education and encourage them forwards. This is reflected by one young adult who described the outcomes of AP as intrinsic to the individual rather than focused on objective achievements: school's about numbers in my eyes ... they want you to pass, pass rates, very important, Ofsted, very important. The Bass-ment [AP he attended], yes Ofsted's important to them but they are more for the people they're not more for the results. But obviously they get their results by people, hopefully (Josh)

The 'hopefully' at the end of this sentence conveys an awareness of the challenging circumstances AP attendees have experienced and will likely go on to face. Realistically the onward transitions of the young people who attend AP are likely to be more complex than average and therefore present challenges when attempting to conceptualise and measure success within this field of education. 


\section{Flexibility}

Alongside the relational nature of AP, it was the flexibility found in this context that young adults recalled most frequently. Broadly there was freedom in relation to behaviour and learning, one young adult conceptualised the flexibility found within AP as there being a:

little bit more of freedom and responsibility (Dean)

So, while young people were in a more grown up environment they were expected to respond to this in kind. Of course, this would not always be simply achieved, and another young adult articulated the tension between authority and discipline navigated by staff in AP:

they wouldn't be too disciplined but they'd still have some authority just to show you what actual college and life's actually going to be like (Phil)

In line with this he also recollected staff engaging in banter: they'll either just laugh about it or they'll say something back to you to make you laugh and think, okay fair enough (Phil)

So there is a different culture but also skilled staff engagement where this culture has not yet begun to shape pupil behaviour. In relation to learning, flexibility involved tailoring work to pupils' interests and young adults reported having the time to explore and really get into the topics they were studying. Frequently personalisation revolved around staff knowing young people and therefore being in a position to use their interests to engage them, whether in a specific situation or in learning more generally:

They work very gradually and build up over time, they picked on what I wanted to do, what I was interested in (Lucy)

There seemed to be a connection between supporting young people to pursue their interests and structural flexibility: 
the way I always saw school, it was always, this is what you are doing. There is no freedom. You're doing English at this hour on this day ... The Bass-ment [AP he attended] they gave me the opportunity to do, pursue what I wanted to do. School never interested me because it was nothing I was interested in (Carl)

Alongside this Carl recalled that he used to hate maths in school but now commonly undertook mathematical processes in his job. It would seem that choice is again here the underlying dynamic for engagement.

Dean attended two APs to make up a full-time placement overall. Talking about other students who attended a general educational setting with him he said:

one went and done brick laying, the other girl went and done hair and beauty and then me and the other guy would go Bass-ment [music focussed AP]. That's because that's what we wanted to do ... regardless of how we are in another environment, i.e. school or wherever, in that environment we work, we work well (Dean)

Here the connection to a young person's interests can be seen to be motivating their engagement in AP. For other young adults their willingness to engage was much more instrumentally based: half the stuff I learnt in school I thought, I'm not going to do this when I'm older ... if I didn't think it was going to help me then I didn't really want to do it (Sam) Instrumentality was often framed by young adults as relevance. There were experiences of interview and CV preparation and of setting up work experience being particularly influential: when I was there [the work experience placement] it was like I could see myself being there full-time and it gave me the drive to want to carry on (Charlotte) Finally, alongside instrumental engagement with learning other young adults reported a flexible environment in which they experienced both support without judgement and differentiation: 
I really really enjoyed it, they always seemed just to be able to make it more applicable ... they sort of tailored everything for you but um, like if you were more capable of doing something they'd help you sort of achieve what you needed to, um, at the same time they wouldn't make you feel stupid if you couldn't do something like by setting you in a lower set or something (Liz)

\section{Negative experiences}

The AP experienced by the young adults who took part in this research had been in large part positive, this is common in this area of research (McCluskey, Riddell, and Weedon 2015). There were however negative experiences of AP which are just as important for understanding the dynamics at play in this area of schooling. There were also some recurring problems which should be the focus of future policy and practice development. Young adults' negative experiences generally coalesced around the themes of appropriate learning and transitions which will be discussed in turn.

There seemed to be a perception amongst some of the young adults that the learning which happened in AP was not comparable to the academic learning which happens in mainstream school. One young adult conceptualised this as the teaching in AP being better but the work in mainstream was more what they needed. This leads into a theme around examinations. One young adult was told they would be able to take GCSEs so as to be able to go to college, however once they secured a college place the AP provider didn't pursue this and the young adult didn't complete these exams. Another young adult was told they would not be able to take higher tier exams, this led to them disengaging from the AP and working for their GCSEs at home. These accounts are concerning and in line with some of the existing criticisms levelled against AP (Gazeley 2010; McCluskey, Riddell, and Weedon 2015). It was certainly the case 
that a number of the young adults who took part in this research were academically able - two had gone on to university and another three had made use of evening classes to gain career related qualifications. As a response to this persistent issue it would seem to make sense that part of the role Local Authorities could play in relation to AP (DfE 2016) should be monitoring of the availability of qualifications to young people attending.

A number of young adults' recounted experiences of the AP they were attending shutting down, sometimes without notice. AP tends to lack the overall level of resourcing and secured funding found in mainstream settings which leads to this instability and can limit the availability of qualified staff. Some young adults were however positive about the presence of resources to pursue particular interests. This makes sense in the context of, but was not limited to, the focus on particular subject areas - for example music production - within some AP settings.

There are three ways in which transitions occur in relation to AP all of which were raised in the research. The first is the transition into AP in the first place, for those who mentioned this it was an experience marked by apprehension of being in a new place with young people who were perceived to have problems or to be bad influences. Although not an entirely unfounded fear it was far more common for young adults to retrospectively reflect on positive peer relationships within AP settings. Indeed, as seen above one interviewee remarked on the positive relationships that other young people at the AP had with staff which meant they were more likely to fall in line with this upon their arrival. The second type of transition is where a young person is returning to a mainstream environment, reflections on this experience were of spending too long in an AP environment before reintegration or of a lack of ability to influence this process. The final transition type is where a young person moves on from AP at the age of 16. Reflections 
on this were of the challenge of moving on from a situation where extensive support had been in place.

These issues of transition are somewhat in line with the existing body of research about exclusion and the difficulties of the move from primary to secondary school - particularily the presence of 'appropriate support mechanisms' (Trotman, Tucker, and Martyn 2015, 250) and the beginning of an emerging policy interest in the transition from AP to post-16 education (Tate and Greatbatch 2017).

\section{The impact of attending AP}

The overall impact of attending AP was insightfully articulated by Jason in the following terms: when you get kicked out of school I think it kind of makes you feel like you're not going to achieve anything and that's why a lot of people don't do the work or don't do this don't do that but if they have the right teacher or the right learning atmosphere they know they can, they're not just going to end up not doing anything but they can like go where they wanna go (Jason)

Here we have the initial impact of marginalisation and exclusion from mainstream schooling but also of the possibilities that can be found in AP. Young adults talked about a number of distinct outcomes, often framed as changes brought about by attending AP. Dean experienced a level of motivation that had not been present when attending mainstream school:

It gave me a sense of purpose, I had something to get up to and look forward to and do (Dean)

The ability of AP to motivate was also experienced as mitigation against adverse life experiences: 
kept me interested in the subject that I loved even when I was feeling pretty crap about everything else (Liz)

This reminds us that when considering outcomes, it is important to keep in mind that there may well be ways in which successful AP exists as a bulwark against further adversity at a time of significant instability in a young person's life.

A number of young adults shared that for them the influence of AP had been a calming one. Before attending AP John's school's list of his misdeeds was, in his words, 'as long as you like'. He had clearly presented very difficult behaviour at mainstream, had undiagnosed dyslexia and in addition was undergoing stressful life events. For him the break of AP allowed a different mind-set to form which was of significant help when re-engaging with mainstream schooling. This notion of AP as providing a space in which new possibilities could be imagined by young people is important and can be seen as underlying a number of the outcomes reported by young adults. For Jeremy as a result of the calming influence of AP he became happier and more open to others:

like when I was at PLH [AP he attended] I was a lot less angry, it took a lot more for me to get angry ... it just, it calmed me down, it changed my personality I started laughing, joking around with everyone rather than with just a select few people (Jeremy)

Sam connected learning to take a calmer approach to the example set by staff in AP:

I think the way they handled us differently to the other schools, it sort of showed you different way (Sam)

Building communication skills was mentioned by a number of young adults, frequently those who had also reported experiences of bullying, and was often connected to developing confidence in talking to people: 
I was really shy, really shy, overly shy. But, yeah, they boosted my confidence more than anything, they taught me how to, how to come out of my shell a bit more (Carl)

And

If I didn't go there then I wouldn't ... be as confident as I am now, I'm not life of the party or anything but I couldn't speak to people before so. I made friends there so it sort of changed my way of thinking (Jenny)

Experiencing a different kind of relationship, with both staff and peers, to that which had been present in mainstream schooling had allowed for the re-imagining of possibilities. Increased confidence also came about because of encouragement from staff which was grounded in reality: not trying to boost you falsely but saying, yes you're good at this, this is what you should work on (Josh)

Confidence was not just in learning but also in relation to being prepared for future work opportunities:

I worked in a pub for about a year [whilst studying at college]... the confidence that I got from being outside of school um, in those centres... helped me to realise that I wasn't incapable of talking to people (Liz)

Sam's experience of AP was of staff connecting in to his future (and present) career ambitions:

I think I sort of had a feeling what I wanted to do anyway, cos I mean I was doing building work while I was in school anyway. But it's good to have someone that you can sometimes talk to and say, yeah, no, and then they put their side across as well ...

[Interviewer: like saying, you want to do that, what about beyond that?] 
Or they might say well, alright yeah maybe that but I think you might be suited more to this, what do you think about that and stuff like that. Not just say yeah that's it, we'll do that, give you maybe other ideas into what they think you might be suited to better as well (Sam)

We see here that Sam was both supported in his ambitions but also explicitly challenged to expand his horizons. Related to this, focus moving forwards was the final outcome of attending AP. For a number of young adults attending AP had been that start of a new phase of life. When interviewed Kim had worked in childcare since leaving AP and was presently a full time mum. She reflected that experiences in AP had focused her ambitions:

you don't really know what you're going to do, but cos they showed so much interest in my future ... it's pretty much it was thanks to them and their support that I am where I am now (Kim)

She then went on to list numerous others with whom she had been at AP who were 'doing something really productive with their life' finishing by saying:

I see them about a few times and they were at college or at uni so yeah they all.. everyone come away with something (Kim)

When interviewed Josh was working as a caretaker, living with his partner and 18 month old child and was well on the way to gaining a diploma as an electrician. He said:

I think if I didn't have The Bass-ment I wouldn't be here now ... It started me doing a lot of stuff (Josh)

Altogether these findings show that many young adults recall AP as a qualitatively different kind of social space compared to their other experiences of schooling. An experience of inherent 
flexibility underpinned by relationships where a new mind-set can form which can in itself lead to a new phase of life.

\section{Discussion}

Hodkinson's 'Careership theory' brings coherence and clarity to the experiences of these young adults. 'Horizons for action' are visible in the young adults' discussions of how their options changed and became shaped by their new context once in AP. It would in fact seem to be the case that this change frequently led to a developed awareness of options that were available to a young person. The researcher would be inclined to conceptualise the move from mainstream to AP as a change of field rather than simple a change of position in the broader field of education. This is due to the qualitatively different nature of the social space reported to be present in AP settings. Thus, the experience of a different field in AP can lead to change in a young person's 'horizons for action'. This change of perspective was seen in numerous articulations of AP as having 'changed my way of thinking'.

The 'decision making process' can be seen when trusted individuals end up playing a part in a young person's career progression. This fits neatly with the prominence and importance ascribed to relationships in AP. The young adult's accounts provided quote after quote mentioning the impact of specific members of staff, frequently by name.

The experience of attending AP itself may well, on reflection, be considered either part of or itself a 'turning point' in a young person's life course. It is helpful to recognise that even if this is true it may well be indiscernible until later on when the young person has become a young adult, thus highlighting the value of conducting retrospective interviews with the young adults in this research project. More broadly it has been shown in the findings that the process of attending 
AP can be considered a turning point in that it led to a changed perspective in relation to self and of what was possible post-16.

Taken together the implications of this theorisation of these findings is that AP can act as a turning point for young people who attend. This is because it offers a qualitatively different social space to that experienced in mainstream schooling. When young people experience a change of field from mainstream to AP they will experience new and refocused horizons for action; it will be an opportunity to reassess previous experiences in light of a new context. In this research young people who had experienced bullying and an associated lack of confidence were able to see themselves in a new sociable light, 'they boosted my confidence'. Others came to a deeper understanding of their ability to choose a calmer response to challenging situations. This was often connected to the different experience in AP, 'it showed you a different way'. Students who for a variety of reasons had all found themselves marginalised and excluded from mainstream school experienced the interest of others in their future. This developed their focus for moving forwards, 'if I didn’t have the Bass-ment I wouldn't be here now'.

\section{Conclusion}

This article is grounded in the reflections of eighteen young adults and puts forward a broadly positive view of what AP schooling can achieve in the life of a young person who has been marginalised and excluded from the mainstream schooling system. Given the experience of AP set out in the method section above it is unlikely that all of these young people experienced outstanding AP practice which far outstripped the practice which is more generally on offer. Indeed, the young adults who took part in this study were not unanimously positive about their experiences of AP. However, it was clear that attending this type of educational setting led to profound changes in many of the participants' perceptions of the opportunities available to them 
and frequently to their trajectory through life from leaving AP to the point of interview. The consequences of this for those attempting to measure the success of this area of schooling are the need to consider longer term monitoring and to focus on the broader understanding of learning articulated as important in the AP setting by young adults involved in this research, particularly providing stability to mitigate against severe adversity in the lives of young people who attend AP settings.

The relevance of 'horizons for action' and the 'decision making process' for conceptualising young peoples' experiences of AP has been discussed above. AP settings are providers of positive and significant relationships. Relationships which can provide a fresh perspective to a young person's experience of schooling, education and the opportunities available to them. To best utilise this, providers should, if indeed they don't already, see themselves as providing on-going support to those who have accessed their provision. They should keep in touch with these young people and provide continuing support and encouragement for them to secure a successful position in life in the longer-term. This would address some of the issues raised above in relation to post-16 transition and could be helpfully supported by policy makers. A requirement could be placed on any commissioner of AP where the young person is not reintegrated into a mainstream setting to procure a period of on-going support from the AP setting where the young person had been placed. Finally, as mentioned above, there is a role for Local Authorities to play in monitoring the availability of qualifications for young people attending AP settings in their locality.

Despite its small scale, this research has developed a theorisation of AP which accounts for the positivity of many young people who attend these settings and conceptualises how this experience might shape their future outcomes. This theorisation can be considered to have wider 
relevance beyond the English context given the congruence within the international literature on AP. Larger scale research is still needed to explore the long term outcomes for young people who attend AP. Alongside this, researchers will also need to consider what success looks like for this population given their marginalisation and exclusion from mainstream schooling can be understood to be driven by marketization and the drive for outcomes.

This research provides a simple conceptual framework which can be used by those involved in the commissioning and delivery of AP to ensure young people marginalised and excluded from mainstream schooling have the opportunity to access effective practice in AP settings. Practice which while still constrained by adverse experiences in the lives of the young people who attend may go some way towards ameliorating previous negative educational experiences and provide a turning point towards re-engagement in learning. 


\section{References}

Attwood, Gaynor, Paul Croll, and Jane Hamilton. 2004. "Challenging students in further education: themes arising from a study of innovative FE provision for excluded and disaffected young people." Journal of Further and Higher Education 28 (1): 107-119. doi:

$10.1080 / 0309877032000161850$.

Cajic-Seigneur, Magdalena, and Ann Hodgson. 2016. "Alternative educational provision in an area of deprivation in London." London Review of Education 14 (2): 25-37. doi:

10.18546/LRE.14.2.03.

Cullen, Kairen, and Joyce Monroe. 2010. "Using positive relationships to engage the disengaged: An educational psychologist-initiated project involving professional sports input to a pupil referral unit." Educational and Child Psychology 27 (1): 64-78.

DfE. 2016. "Educational Excellence Everywhere." https://www.gov.uk/government/uploads/system/uploads/attachment_data/file/508447/Education al_Excellence_Everywhere.pdf.

DfE, 2018. "Investigative research into alternative provision."

https://assets.publishing.service.gov.uk/government/uploads/system/uploads/attachment_data/file /748910/Investigative_research_into_alternative_provision.pdf 
Farouk, Shaalan. 2014. "From Mainstream School to Pupil Referral Unit: A Change in Teachers' Self-Understanding." Teachers and Teaching: Theory and Practice 20 (1): 19-31. doi: 10.1080/13540602.2013.848518.

Feltcher, John, Steve Strand, and Sally Thomas. 2015. "The Educational Progress of Looked After Children in England Technical Report 1: Secondary School Progress and Attainment." Rees Centre: University of Oxford. http://reescentre.education.ox.ac.uk/wordpress/wpcontent/uploads/2015/11/EducationalProgressLookedAfterChildrenTechnical-Report1_Nov2015.pdf.

Garner, Philip. 1996. "A la Recherche du Temps Perdu: Case-study Evidence from Off-site and Pupil Referral Units." Children \& Society 10 (3): 187-96. doi: 10.1111/j.10990860.1996.tb00468.x.

Gazeley, L. 2010. "The role of school exclusion processes in the re-production of social and educational disadvantage.” British Journal of Educational Studies 58 (3): 293-309. doi: $10.1080 / 00071000903520843$.

Grundy, Wendy, and Sonia Blandford. 1999. "DEVELOPING A CULTURE FOR POSITIVE BEHAVIOUR MANAGEMENT." Emotional \& Behavioural Difficulties 4 (3): 5-9. doi: $10.1080 / 1363275990040302$. 
Hodkinson, Phil. 2008. "Understanding career decision-making and progression: Careership revisited.” John Killeen Memorial Lecture, London, October 16th. http://www.crac.org.uk/CMS/files/upload/fifth_johnkilleenlecturenotes.pdf.

Hutchison, Andrew John, Lynne Halley Johnston, and Jeff David Breckon. 2010. "Using QSRNVivo to facilitate the development of a grounded theory project: an account of a worked example.” International Journal of Social Research Methodology 13 (4): 283-302. DOI: $\underline{10.1080 / 13645570902996301}$

Jalali, Rheanne, and Gavin Morgan. 2017. “'They won't let me back.' Comparing student perceptions across primary and secondary Pupil Referral Units (PRUs).” Emotional \& Behavioural Difficulties: 1-14. doi: 10.1080/13632752.2017.1347364.

Kilpatrick, Rosemary, Claire McCartan, and Penny McKeown. 2007. "Out of the Box Alternative Education Provision (AEP) in Northern Ireland." http://dera.ioe.ac.uk/6707/7/no_45_final-3_Redacted.pdf.

Lanskey, Caroline. 2014. "Up or down and out? A systemic analysis of young people's educational pathways in the youth justice system in England and Wales." International Journal of Inclusive Education 19 (6): 568-582. doi: 10.1080/13603116.2014.961675

Lumby, J. 2012. "Disengaged and disaffected young people: surviving the system." British Educational Research Journal. 38 (2): 261-279. doi: 10.1080/01411926.2010.541553. 
Malcolm, Andrew. 2015. "Alternative provision as an educational option: understanding the experiences of excluded young people." Professional Doctorate Thesis. University of Bedfordshire. http://hdl.handle.net/10547/608337.

Malcolm, Andrew. 2018a. "Heads of alternative provision: committed to realising young peoples' potential in an unregulated market." International Journal of Inclusive Education Published online. doi: $\underline{10.1080 / 13603116.2018 .1470686}$

Malcolm, Andrew. 2018b. "Exclusions and alternative provision: piecing together the picture." Emotional and Behavioural Difficulties 23 (1): 69-80. doi: 10.1080/13632752.2017.1366099

McCluskey, Gillean. 2008. "Exclusion from school: what can 'included' pupils tell us?” British Educational Research Journal 34 (4): 447-466. doi: 10.1080/01411920701609331.

McCluskey, Gillean, Sheila Riddell, and Elisabet Weedon. 2015. "Children's Rights, School Exclusion and Alternative Educational Provision." International Journal of Inclusive Education 19 (6): 595-607. doi: 10.1080/13603116.2014.961677.

McGregor, Glenda, Martin Mills, Kitty te Riele, and Debra Hayes. 2014. "Excluded from school: getting a second chance at a 'meaningful' education." International Journal of Inclusive Education 19 (6): 608-625. doi: 10.1080/13603116.2014.961684. 
McGregor, Glenda, and Martin Mills. 2012. "Alternative education sites and marginalised young people." International Journal of Inclusive Education 16 (8): 843-862. doi:

$10.1080 / 13603116.2010 .529467$.

Mills, Martin, Peter Renshaw, and Lew Zipin. 2013. “Alternative Education Provision: A dumping ground for 'wasted lives' or a challenge to the mainstream?" Social Alternatives 32 (2): $13-18$.

Morgan, Ann, Donna Pendergast, Raymond Brown, and Deborah Heck. 2015. "Relational ways of being an educator: trauma-informed practice supporting disenfranchised young people" International Journal of Inclusive Education 19 (10): 1037-1051. doi: $10.1080 / 13603116.2015 .1035344$.

Nicholson, Laura J., and Dave W. Putwain. 2015. "Facilitating re-engagement in learning: A disengaged student perspective." Psychology of Education Review 39 (2): 37-41.

O'Gorman, Eva, Nancy Salmon and Carol-Anne Murphy. 2016. "Schools as sanctuaries: A systematic review of contextual factors which contribute to student retention in alternative education." International Journal of Inclusive Education 20 (5): 536-551. doi: 10.1080/13603116.2015.1095251.

Osler, Audrey, Cathy Street, Marie Lall, and Kerry Vincent. 2002. "Not a problem? Girls and exclusion from school.” London: New Policy Institute. 
Pillay, Jace, Helen Dunbar-Krige, and Jacques Mostert. 2013. "Learners with behavioural, emotional and social difficulties' experiences of reintegration into mainstream education." Emotional \& Behavioural Difficulties 18 (3): 310-26. doi: 10.1080/13632752.2013.769709.

Pirrie, Anne, Gale Macleod, Mairi Ann Cullen, and Gillean McCluskey. 2011. "What happens to pupils permanently excluded from special schools and pupil referral units in England?" British Educational Research Journal 37 (3): 519-38. doi: 10.1080/01411926.2010.481724.

Pomeroy, Eva. 1999. "The teacher-student relationship in secondary school: insights from excluded students.” British Journal of Sociology of Education 20 (4): 465-482. doi: $10.1080 / 01425699995218$.

Russell, Lisa, and Pat Thomson. 2011. "Girls and gender in alternative education provision." Ethnography \& Education 6 (3): 293-308. doi: 10.1080/17457823.2011.610581.

Solomon, Mike, and Gaby Thomas. 2013. "Supporting behaviour support: developing a model for leading and managing a unit for teenagers excluded from mainstream school." Emotional \& Behavioural Difficulties 18 (1):44-59. doi: 10.1080/13632752.2012.689566.

Tate, Sue, and David Greatbatch. 2017. "Alternative Provision: Effective Practice and Post 16 Transition." Department for Education. 
https://www.gov.uk/government/uploads/system/uploads/attachment_data/file/585550/Alternativ e_provision_effective_practice_and_post-16_transition.pdf.

Thomson, Pat. 2014. "What's the alternative? Effective support for young people disengaging from the mainstream: Literature Review." https://alternativeducationresearch.files.wordpress.com/2014/10/literature-review-final-15-1014.pdf.

Thomson, Pat, and Jodie Pennacchia. 2014. "What's the alternative? Effective support for young people disengaging from mainstream education.” The Prince's Trust.

https://alternativeducationresearch.files.wordpress.com/2014/10/education-report-final-14thoctober-2014.pdf.

Thomson, Pat, and Jodie Pennacchia. 2015. "Hugs and behaviour points: Alternative education and the regulation of 'excluded' youth.” International Journal of Inclusive Education 20 (6): 622640. doi: $10.1080 / 13603116.2015 .1102340$.

Trotman, Dave, Stanley Tucker, and Madeline Martyn. 2015. "Understanding problematic pupil behaviour: perceptions of pupils and behaviour coordinators on secondary school exclusion in an English city." Educational Research 57 (3):237-53. doi: 10.1080/00131881.2015.1056643. 